\title{
A Unit-Decade Compatibility Effect in German Number Words
}

\author{
H.C. Nuerk, U. Weger and K. Willmes
}

\section{(2) OpenEdition \\ 1 Journals}

\section{Electronic version}

URL: http://journals.openedition.org/cpl/149

DOI: $10.4000 / \mathrm{cpl} .149$

ISSN: $1379-6100$

\section{Publisher}

Centre PsyCLÉ

\section{Printed version}

Date of publication: 1 April 2002

\section{Electronic reference}

H.C. Nuerk, U. Weger and K. Willmes, «A Unit-Decade Compatibility Effect in German Number Words », Current psychology letters [Online], 2002/1, 7 | 2002, Online since 04 September 2003, connection on 08 September 2020. URL : http://journals.openedition.org/cpl/149; DOl : https://doi.org/10.4000/cpl. 149

This text was automatically generated on 8 September 2020

(c) All rights reserved 


\section{A Unit-Decade Compatibility Effect in German Number Words}

H.C. Nuerk, U. Weger and K. Willmes 